\title{
Elderly suicides in Denizli, Turkey: a retrospective study from 2011 to 2020
}

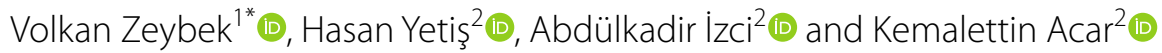

\begin{abstract}
Background: Although suicide rates and methods used may vary according to society, gender, and age there are epidemiological studies reporting that suicide rates increase with advanced age in all societies, particularly accelerating after the age of 65 years. This study aimed to investigate the demographic data and suicide characteristics — such as the location and method, among others - of the elderly suicide deaths among forensic deaths between 2011 and 2020 in Denizli, Turkey.

Results: It was determined that elderly suicides constituted $13.8 \%$ of all suicides and increased gradually over the years during the 10-year period. The vast majority of cases were male (82\%). It has been observed that hanging is the most frequently used method. It is also noteworthy that although firearm suicide among men was the second most common method, women do not choose this method at all. The majority of elderly suicides (88.5\%) in Denizli occurred in the home and its annexes.

Conclusions: Suicide prevention programmes should promote the elderly to benefit widely from social and health services. Therefore, there is a need to include widespread home care services and firearms regulations in prevention programmes.
\end{abstract}

Keywords: Elder, Suicide, Autopsy, Hanging, Turkey

\section{Background}

The World Health Organization considers suicide prevention a major public health issue that requires a multidisciplinary approach and intervention. On average, 800,000 people die by suicide each year (World Health Organization 2014, 2019). The increase in life expectancy and the decrease in birth rates lead to an increase in the elderly population in terms of number and relative to the general population (Kaya et al. 2020). Similarly, the elderly population is increasing in Turkey. According to the Turkish Statistical Institute, the elderly population of Turkey has increased by $22.5 \%$ in the last 5 years, reaching $9.5 \%$ of the population and it is estimated to reach $22.6 \%$ of the population of Turkey by 2060 . With an

\footnotetext{
*Correspondence: drvolkanzeybek@gmail.com

${ }^{1}$ Manisa Celal Bayar University Faculty of Medicine Department

of Forensic Medicine, Manisa, Turkey

Full list of author information is available at the end of the article
}

increased in the elderly population, an increase in elderly suicide rate is also expected. Although the incidence of elderly suicides varies internationally and regionally, suicide rates among older adults are generally increasing (TURKSTAT Corporate 2021; Jahn et al. 2015; Karbeyaz et al. 2017).

Epidemiological studies have concluded that suicide rates increase with advanced age in all societies, particularly accelerating after the age of 65 years, with the highest rates are reached after the age of 75 years. In addition, the likelihood of a suicide attempt resulting in death is considerably higher in older adults than in the younger population. However, when compared with suicide cases in the younger population, information about geriatric suicide cases in the media and in the medical literature is considerably lacking. Medical reasons such as physical or mental illnesses, death of the elderly relative, marital conflicts, dependency on others, and economic problems are among the most important factors causing elderly

\section{SpringerOpen}

(c) The Author(s) 2022. Open Access This article is licensed under a Creative Commons Attribution 4.0 International License, which permits use, sharing, adaptation, distribution and reproduction in any medium or format, as long as you give appropriate credit to the original author(s) and the source, provide a link to the Creative Commons licence, and indicate if changes were made. The images or other third party material in this article are included in the article's Creative Commons licence, unless indicated otherwise in a credit line to the material. If material is not included in the article's Creative Commons licence and your intended use is not permitted by statutory regulation or exceeds the permitted use, you will need to obtain permission directly from the copyright holder. To view a copy of this licence, visit http://creativecommons.org/licenses/by/4.0/. 
suicide. Suicide rates and methods used may vary according to society, gender, and age (Juurlink et al. 2004; Karbeyaz et al. 2017; Lutzman et al. 2020; Szücs et al. 2020).

In Denizli-located in the Aegean region-the total population is $1,040,915$ and the population of individuals aged $>65$ years is reported as 119,701. According to 2020 data, although the elderly population in Turkey is $9.5 \%$, $11.5 \%$ of the total population in Denizli are older adults (TURKSTAT Corporate 2021). It was considered that the evaluation of elderly suicides in Denizli, where the average of the elderly population is above the country average, will provide valuable data. The present study aimed to investigate the demographic data and suicide characteristics-such as the location and method, among others-of the elderly suicide deaths among forensic deaths in Denizli between 2011 and 2020.

\section{Methods}

Study approval was obtained from Pamukkale University Non-Interventional Clinical Research Ethics Committee, dated 12 February 2021 and numbered E.17721.

In this retrospective descriptive study, crime scene investigation, examination of deceased, and autopsy reports of cases who have died by suicide over the age of 65 years that experienced classical autopsy in Denizli during 10 years period between the years 2011 and 2020 were examined retrospectively. Only the cases that the judicial authorities stated the cause of death was suicide and did not require further investigation were included in the study. In this context, the files of 564 cases who committed suicide were evaluated. It was determined that $78(13.8 \%)$ of these cases were aged $\geq 65$ years. Out of a total of 564 cases, 78 constituted the study group. Cases were evaluated based on age, sex, distribution of cases according to years, chosen suicide method, crime scene, and place of death.

Data were analysed using SPSS version 21.0 software. Descriptive statistics are given as mean \pm standard deviation for quantitative variables, frequency and percentage for categorical variables. Chi-square and two-group comparison test (Student's $t$, Mann-Whitney $U$ ) were used in the analysis of the data, depending on the type of variable. $P$ values $<0.05$ were considered statistically significant.

\section{Results}

It was observed that a total of 564 forensic autopsies of suicide deaths were carried out in Denizli between 2011 and 2020 , and 78 (13.8\%) of them were aged $\geq 65$ years. According to the distribution of suicide rates by years, the highest rate was found in 2017 (26\%) (Fig. 1).

Of the 78 cases included in the present study, $14(18 \%)$ were women and $64(82 \%)$ were men (ratio of men to women, 4.57). The distribution of the sexes of the cases by years is shown in Fig. 2.

The youngest and oldest cases included were aged 65 and 89 years, respectively, and the mean age was 73.44 ( \pm $6.863)$ years. The age ranges were as follows: 29 (37.2\%) cases aged 65-69 years, $15(19.2 \%)$ aged $70-74$ years, 16 (20.5\%) aged $75-79$ years, $11(14.1 \%)$ aged $80-84$ years and 7 (9\%) aged $\geq 85$ years (Fig. 3). Considering the age range distribution without gender discrimination, it was understood that the high rate in the age range of 65-69 years was statistically significant $\left(P=0.001 \chi^{2}=17.641\right)$.

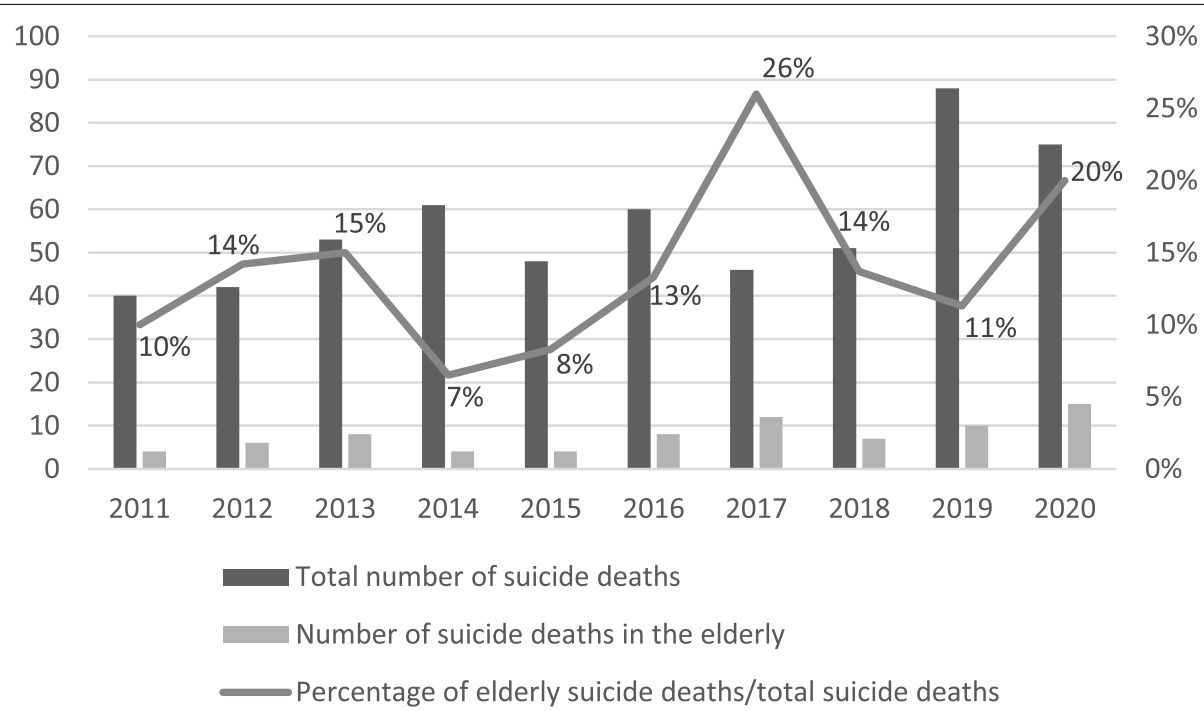

Fig. 1 Distribution of elderly suicide rates by years 

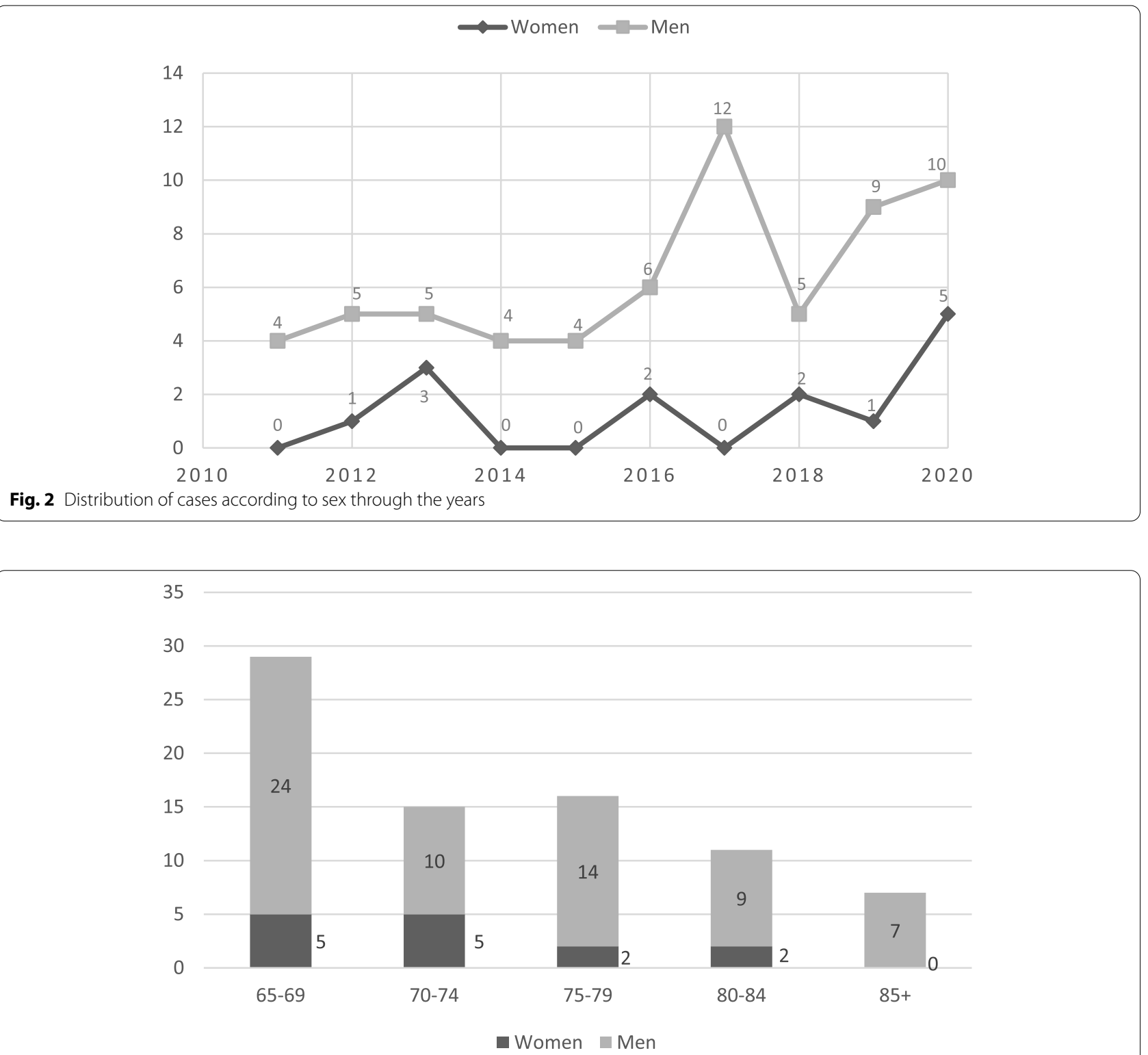

Fig. 3 Distribution of cases by age (years) and sex

The most common methods of suicide included hanging (55.1\%), firearm use (19.2\%) and jumping from a height (14.1\%) (Fig. 4). It was statistically significant fact that that women never chose the use of firearms as a suicide method $\left(P=0.044 \chi^{2}=4.063\right)$.

It was determined that $88.5 \%$ of the suicides occurred in homes and annexes. The places where the cases committed suicide are shown in Table 1 . It was stated that 11 (14.1\%) of the cases lived alone, whereas 31 (39.8\%) lived with their family or friends. The information regarding the families of the 36 patients $(46.2 \%)$ could not be acquired.

\section{Discussions}

In our study, it was determined that elderly suicides constituted $13.8 \%$ of all suicides and increased gradually over the years during the 10-year period in Denizli. In studies conducted in different cities of Turkey, the rate of elderly suicides to the total number of suicides was reportedly between $6.2 \%$ and $11.5 \%$ (Hilal et al. 2010; Karbeyaz et al. 2017; Timur et al. 2017; Akin et al. 2019). Similarly, in studies conducted in different countries, it has been reported that the suicide rate in the elderly group is higher than that in other age groups, and the suicide rate in the elderly is gradually increasing (Özer et al. 2016; 


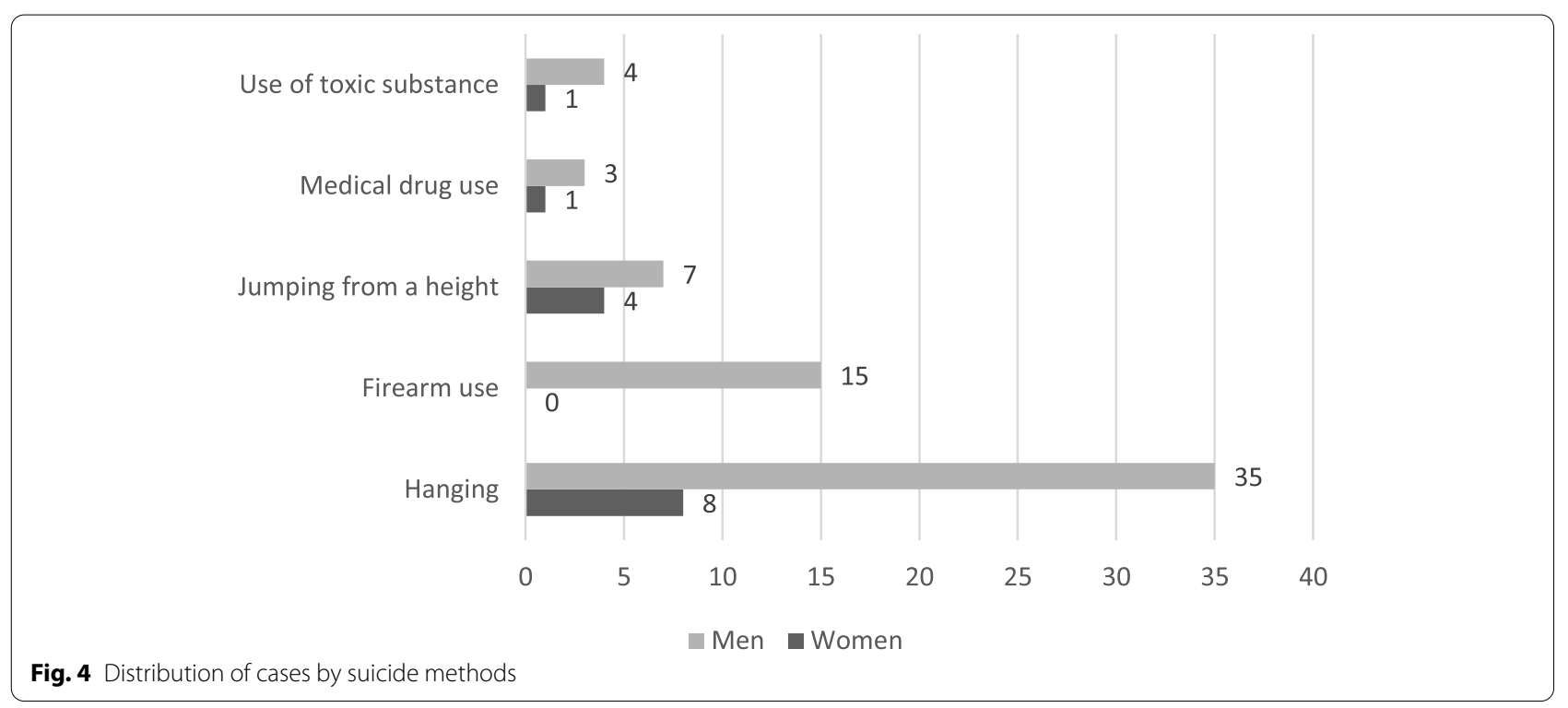

Table 1 Distribution of the places where the cases committed suicide

\begin{tabular}{lll}
\hline Place & $\boldsymbol{n}$ & \% \\
\hline Home and annexes & 69 & 88.5 \\
Rural area & 6 & 7.7 \\
Hospital & 1 & 1.3 \\
Workplace & 1 & 1.3 \\
Hotel & 1 & 1.3 \\
Total & 78 & 100 \\
\hline
\end{tabular}

Steele et al. 2018; Kim and Lee 2020). The fact that the elderly population in Denizli is higher than the average elderly population of Turkey and that the decline in supportive family structure today are thought to be associated with the increase in elderly suicides in Denizli.

Similar to the literature, it was noted that majority of the elderly who committed suicide in Denizli Province (82\%) were men. Similar to the overall population, it has been reported that men showed a trend of committing suicide more frequently in the elderly population, and being a man is a risk factor for elderly suicides (Steele et al. 2018; Crestani et al. 2019; Tan and Cheung 2019; Kim et al. 2019). The higher rate of suicide in men may be attributable to that fact that with the advancing age they are more likely to face factors such as losing social connections and being alone, losing social status more significantly depending on their gender-defined roles, and predisposition to chronic diseases.

According to the Turkish Statistical Institute, it has been reported that most people aged $\geq 65$ years committed suicide by hanging (Özer et al. 2016). Likewise, studies conducted worldwide have revealed that the elderly most frequently commit suicide by hanging (Steele et al. 2018; Crestani et al. 2019; Kim et al. 2019). It has been reported that hanging was the more frequently preferred method of suicide due to its higher lethality and the ready availability of used materials (Karbeyaz et al. 2017; Demir et al. 2018; Crestani et al. 2019). In Denizli, it has been observed that hanging is the most frequently used method among elderly suicides. It is also noteworthy that although firearm suicide among men was the second most common method, women do not choose this method at all. Reportedly, there is a strong relationship between firearm ownership and firearm suicide rate, and that the number of men who own a firearm gradually increased after 1990 (Siegel and Rothman 2016). It has been stated that firearm suicide is mostly preferred by men when compared with women, since there is a need for more information on how a firearm works and the firearm causes a dramatic deformity (Crestani et al. 2019). In our study, it was observed that jumping from a height was the second most common method of suicide in women. According to TURKSTAT data, it was noted that jumping from a height was the second most common method among elderly female suicides in Turkey, and in other studies, it was the second in Erzurum and the third in Izmir (Özer et al. 2016; Timur et al. 2017; Akin et al. 2019).

Spending more time at home owing to factors such as difficulty in walking, limitation of movement, and social isolation was found to be associated with higher incidence of suicides at home in the elderly (Conwell and Thompson 2008; Rahimi et al. 2015; Steele et al. 2018). Consistent with the literature, the majority of elderly 
suicides (88.5\%) in Denizli occurred in the home and its annexes.

Since no information about the cause of suicide could be obtained from the crime scene investigation and examination of deceased and autopsy reports, the reasons for suicide of the cases were not included in this study. Another reason of cause of suicide for not being included in the study is that the information on the presence or absence of psychiatric diseases in the history of the cases could not be acquired. Studies have shown that clinical and psychosocial factors; a history of psychiatric or mental disorder, previous suicide attempts, a history of alcohol abuse, stressful life events, and lack of social support all increase the risk of suicide (Kalkan Oguzhanoglu et al. 2018; Moitra et al. 2021).

\section{Conclusions}

In conclusion, in our study, that elderly men had higher rate of suicide than elderly women, hanging was the most frequently used method, and the elderly most frequently committed suicide at home. In addition, it was determined that firearm suicide is the second most common method in elderly men. Suicide prevention programmes should promote the elderly to benefit widely from social and health services. Therefore, there is a need to include widespread home care services and firearms regulations in prevention programmes.

\section{Acknowledgements}

Not applicable.

\section{Authors' contributions}

KA: supervision, guidance, and editing. HY, Al: performing the practical work, statistical analysis. VZ: creating the research idea and design and writing of the main text. All authors have read and approved the final manuscript.

\section{Funding}

The authors declare that they have received no funding for conducting this study.

\section{Availability of data and materials}

All data generated or analyzed during this study are included in this published article.

\section{Declarations}

\section{Ethics approval and consent to participate}

Study approval was obtained from Pamukkale University Non-Interventional Clinical Research Ethics Committee, dated 12 February 2021 and numbered E.17721.

\section{Consent for publication}

The authors give consent for the article to be published in Egyptian Journal of Forensic Sciences.

\section{Competing interests}

The authors declare that they have no competing interests.

\section{Author details}

${ }^{1}$ Manisa Celal Bayar University Faculty of Medicine Department of Forensic Medicine, Manisa, Turkey. ${ }^{2}$ Pamukkale University Faculty of Medicine Department of Forensic Medicine, Denizli, Turkey.

Received: 11 November 2021 Accepted: 6 January 2022

Published online: 14 January 2022

\section{References}

Akin U, Sunay Yavuz M, Tokdemir M (2019) Deaths over 65 years of age alleged suicide. Med Sci 8:861-866. https://doi.org/10.5455/medscience.2019. 08.9099

Conwell Y, Thompson C (2008) Suicidal behavior in elders. Psychiatr Clin North Am 31:333-356

Crestani C, Masotti V, Corradi N et al (2019) Suicide in the elderly: a 37-years retrospective study. Acta Biomedica 90:68-76. https://doi.org/10.23750/ abm.v90i1.6312

Demir S, Yazar ME, Kurtuluş Dereli A, Acar K (2018) Denizli'deki Intihar Ölümlerinin Analizi 10 Yıllık Retrospektif Otopsi Çalışması. Bull Legal Med 23:93-99. https://doi.org/10.17986/blm.2017136922

Hilal A, Akçan R, Eren A et al (2010) Forensic geriatric deaths in Adana, Turkey. Arch Gerontol Geriatr 50:e9-e12. https://doi.org/10.1016/j.archger.2009. 04.009

Jahn DR, Poindexter EK, Cukrowicz KC (2015) Personality disorder traits, risk factors, and suicide ideation among older adults. Int Psychogeriatr 27:1785-1794. https://doi.org/10.1017/S1041610215000174

Juurlink DN, Herrmann N, Szalai JP et al (2004) Medical illness and the risk of suicide in the elderly. Arch Intern Med 164:1179-1184. https://doi.org/10 1001/archinte.164.11.1179

Kalkan Oguzhanoglu N, Ugurlu TT, Acar K, Atesci F (2018) A psychological and social perspective on completed suicides in Western Anatolia, Turkey: a case-control psychological autopsy study. Dusunen Adam J Psychiatry Neurol Sci 31:331-339. https://doi.org/10.5350/DAJPN2018310401

Karbeyaz K, Çelikel A, Emiral E, Emiral GÖ (2017) Elderly suicide in Eskisehir, Turkey. J Forensic Leg Med 52:12-15. https://doi.org/10.1016/j.fflm.2017. 06.004

Kaya A, Tosun Tasar P, Meral O et al (2020) The characteristics of older people suicides by sex and age subgroups. Leg Med 46:101721. https://doi.org/ 10.1016/j.legalmed.2020.101721

Kim G, Lee MA (2020) Age discrimination and suicidal ideation among Korean older adults. Am J Geriatr Psychiatry 28:748-754. https://doi.org/10. 1016/j.jagp.2019.12.002

Kim JW, Jung HY, Won DY et al (2019) Suicide trends according to age, gender, and marital status in South Korea. Omega (United States) 79:90-105. https://doi.org/10.1177/0030222817715756

Lutzman M, Sommerfeld E, Ben-David S (2020) Loneliness and social integration as mediators between physical pain and suicidal ideation among elderly men. Int Psychogeriatr 33:453-459. https://doi.org/10.1017/S1041 $61022000112 X$

Moitra M, Santomauro D, Degenhardt L et al (2021) Estimating the risk of suicide associated with mental disorders: a systematic review and metaregression analysis. J Psychiatr Res 137:242-249. https://doi.org/10.1016/J. JPSYCHIRES.2021.02.053

Özer E, Gümüş B, Balandiz H et al (2016) Evaluation of geriatric suicides in Turkey. J Forensic Leg Med 44:158-161. https://doi.org/10.1016/j.jflm. 2016.10.016

Rahimi R, Ali N, Noor SM et al (2015) Suicide in the elderly in Malaysia. Malays J Pathol 37:259-263

Siegel M, Rothman EF (2016) Firearm ownership and suicide rates among US men and women, 1981-2013. Am J Public Health 106:1316-1322

Steele IH, Thrower N, Noroian P, Saleh FM (2018) Understanding Suicide Across the Lifespan: A United States Perspective of Suicide Risk Factors, Assessment \& Management. J Forensic Sci 63:162-171. https://doi.org/10.1111/ 1556-4029.13519

Szücs A, Szanto K, Wright AGC, Dombrovski AY (2020) Personality of late- and early-onset elderly suicide attempters. Int J Geriatr Psychiatry 35:384-395. https://doi.org/10.1002/gps.5254 
Tan YM, Cheung G (2019) Self-harm in adults: a comparison between the middle-aged and the elderly. NZMJ 132:1489

Timur O, Tasar PT, Ulusoy MG et al (2017) Autopsies in the elderly: Erzurum study. J Forensic Leg Med 52:143-147. https://doi.org/10.1016/j.ffm.2017. 09.002

TURKSTAT Corporate. https://data.tuik.gov.tr/Bulten/Index?p=|statistiklerleYaslilar-2020-37227. Accessed 11 June 2021

World Health Organization (2014) Preventing suicide: a global imperative. https://www.who.int/publications/i/item/9789241564779. Accessed 21 June 2021

World Health Organization (2019) Suicide in the world: global health estimates

\section{Publisher's Note}

Springer Nature remains neutral with regard to jurisdictional claims in published maps and institutional affiliations.

\section{Submit your manuscript to a SpringerOpen ${ }^{\circ}$ journal and benefit from:}

- Convenient online submission

- Rigorous peer review

- Open access: articles freely available online

- High visibility within the field

- Retaining the copyright to your article

Submit your next manuscript at $\boldsymbol{\nabla}$ springeropen.com 